\title{
Predicting Outcomes of Penetrating Cardiovascular Injuries at a Rural Center by Different Scoring Systems
}

\author{
Ali Ahmet Arikan ${ }^{1}$, MD; Emre Selçuk², MD; Fatih Avni Bayraktar², MD
}

DOI: 10.21470/1678-9741-2019-0403

\begin{abstract}
Objective: To compare the anatomical and physiological scoring systems and the outcomes of surgical management of penetrating cardiovascular trauma at a rural center.

Methods: Seventy-seven patients underwent emergency surgery at our center between January/2012 and October/2018 due to penetrating cardiovascular trauma. Injury Severity Score (ISS), Revised Trauma Score (RTS), New Injury Severity Score (NISS), and Trauma and Injury Severity Score (TRISS) were calculated. The validation of these risk scores to predict mortality was assessed by the area under the receiver operating characteristic curve analysis.

Results: All trauma scores were correlated with mortality. As ISS, NISS, and TRISS values increased and RTS values decreased, the mortality rate increased. The area under the curve (AUC) in the
\end{abstract}

receiver operating characteristic curve analysis was 0.943 for TRISS, 0.915 for RTS, 0.890 for ISS, and 0.896 for NISS ( $P<0.001$ for each). Logistic regression analysis revealed that scores were correlated with mortality $(P<0.001$ for each). By investigating cardiac injuries alone, only TRISS and RTS results correlated with mortality for cardiac injuries (Mann-Whitney $U$ test, $P=0.003$ and $P=0.01$, respectively). The AUC was only statistically significant for TRISS and RTS (AUC $=0.929$, $P<0.05$ for both). For vascular injuries, all the scores were significantly correlated with in-hospital mortality (Mann-Whitney $U$ test, $P<0.001$ for each). TRISS had the highest AUC (AUC $=0.946, P<0.001$ ).

Conclusion: TRISS has the highest predictivity for in-hospital mortality in patients with penetrating cardiovascular trauma.

Keywords: Rural Hospitals. Vascular System Injuries. Injury Severity Score. Penetrating Wounds. Heart Injuries. Area Under Curve.

\section{Abbreviations, acronyms \& symbols}

$\begin{array}{ll}\text { AIS } & =\text { Abbreviated Injury Scale } \\ \text { AUC } & =\text { Area under the curve } \\ \text { CI } & =\text { Confidence interval } \\ \text { EDT } & =\text { Emergency department thoracotomy } \\ \text { GCS } & =\text { Glasgow Coma Scale } \\ \text { ISS } & =\text { Injury Severity Score } \\ \text { NISS } & =\text { New Injury Severity Score } \\ \text { NPV } & =\text { Negative predictive value } \\ \text { OR } & =\text { Odds ratio } \\ \text { PPV } & =\text { Positive predictive value } \\ \text { ROC } & =\text { Receiver operating characteristic } \\ \text { RR } & =\text { Respiratory rate } \\ \text { RTS } & =\text { Revised Trauma Score } \\ \text { SAP } & =\text { Systolic arterial pressure } \\ \text { SBP } & =\text { Systolic blood pressure } \\ \text { SD } & =\text { Standard deviation } \\ \text { TRISS } & =\text { Trauma and Injury Severity Score }\end{array}$

'Department of Cardiovascular Surgery, Kocaeli University Medical Faculty, Kocaeli, Turkey.

${ }^{2}$ Department of Cardiovascular Surgery, Muş State Hospital, Muş, Turkey.

This study was carried out at the Department of Cardiovascular Surgery, Muş State Hospital, Muş, Turkey.

\section{INTRODUCTION}

Trauma involving the cardiovascular system is a lifethreatening condition where immediate intervention is critical. Penetrating trauma on the cardiovascular system usually occurs as a result of violence involving firearms or sharp materials and can present with a wide range of clinical severities and heterogeneous accompanying organ injuries. According to Turkish Statistical Institute's 2017 data, 4.5\% of all deaths in the country were due to injury and poisoning, and it is the leading cause of death in the population between the ages of 15 and 34 years ${ }^{[1,2]}$. About $70 \%$ of the homicides in the country are related to penetrating mechanisms (impact of firearms or sharp force) ${ }^{[3]}$. The therapy of penetrating cardiovascular injuries is a challenge not only due to the complexity of the anatomical neighbors of cardiovascular structures but also because of its interactions with other organs and systemic results of hemorrhage. Results of cardiovascular trauma in large centers have already been

Correspondence Address:

Ali Ahmet Arikan

(iD) https://orcid.org/0000-0002-9599-1577

Kabaoğlu Mahallesi, Baki Komsuoğlu Bulvarı No:515, Kocaeli Üniversitesi Hastanesi, 2.Kat Kalp ve Damar Cerrahisi Servisi, Umuttepe/Izmit/ Kocaeli/Turkey Zip Code: 41380

E-mail: dr_aarikan@hotmail.com 
published, but less is known about rural centers ${ }^{[4]}$. Different health politics are used to provide sufficient health care in rural regions worldwide ${ }^{[5-8]}$. In Turkey, cardiac and vascular systems surgeries are both managed by the cardiovascular surgeon, and the rural areas are obligatory service zones for clinicians to give availability and accessibility to health care services in all geographic areas. Due to the regulations of the ambulance organization, all cardiovascular trauma patients are referred to the study center, which is the only center providing a cardiovascular surgeon in the region and is serving a rural area with 400,000 inhabitants ${ }^{[0]}$. The facilities of our study hospital were consistent with the definition of a rural level 3 trauma center ${ }^{[10]}$.

Scoring systems are well-established tools in trauma epidemiology, quality assurance, and outcome prediction. The Abbreviated Injury Scale (AIS) is used to classify blunt and penetrating trauma ${ }^{[11-14]}$. To numerically express the severity of a traumatized patient, the Injury Severity Score (ISS), New Injury Severity Score (NISS), Revised Trauma Score (RTS), and Trauma and Injury Severity Score (TRISS) emerged ${ }^{[15-18]}$.

As no specific tool for the prediction of in-hospital mortality for penetrating cardiovascular trauma in rural centers is wellestablished, correlations of the ISS, NISS, RTS, and TRISS with patient outcomes were investigated. We evaluated the results of both cardiac and vascular traumas to validate a single scoring system for cardiovascular trauma to be used by the cardiovascular surgeon. Additionally, a separate analysis was also performed for cardiac and noncardiac injuries (involving only vascular trauma).

\section{METHODS}

The institution's approval for retrospective research and the approval from the ethical committee were obtained. This single-center retrospective cohort study included all patients with penetrating cardiac and/or vascular trauma between January/2012 and October/2018 at Muş State Hospital. All the patients' data were available in the hospital's electronic records. All surgically treated trauma patients $>14$ years old and admitted following penetrating injury to a named blood vessel and/or cardiac injury were included in the study.

Seventy-seven patients met the inclusion criteria. Patients' demographic data, comorbid diseases, vital signs (pulse rate, respiratory rate, and blood pressure), penetrating trauma mechanism, anatomic location of the injury, accompanying organ injuries, operative procedures, and in-hospital mortality were evaluated. ISS, NISS, RTS, and TRISS (regarding predicting death rate) for penetrating trauma were calculated for each trauma victim. The main characteristics of the scoring systems are presented in Table 1. The mentioned trauma scores of the patients who survived and the ones who did not were compared.

\section{Statistical Analysis}

The categorical variables were presented as counts and frequencies, and continuous variables as mean and standard deviation. Chi-square test or Fisher's exact test was used for comparison between the categorical variables. Student's $t$-test or Mann-Whitney $U$ test was used to compare the continuous variables. The performance of the risk scores was assessed using receiver operating characteristic (ROC) curves and univariate logistic regression analysis. Sensitivity, specificity, and positive and negative predictive values for mortality prediction for each score were calculated. A $P$-value of 0.05 was considered statistically significant. The IBM SPSS Statistics software (SPSS, Chicago, Illinois, United States of America), version 23.0, was used for all statistical analyses.

Table 1. Variables and calculation of ISS, NISS, RTS, and TRISS.

\begin{tabular}{|c|c|c|}
\hline Scores & Variables & Calculation \\
\hline ISS & $\begin{array}{l}\text { Highest AIS grade in each of the three most severely } \\
\text { injured ISS body regions }\end{array}$ & Sum of [(three most weighted injury per region $\left.)^{2}\right]$ \\
\hline NISS & $\begin{array}{l}\text { Highest three AIS grades of injuries, irrespective of ISS } \\
\text { body regions }\end{array}$ & Sum of [(three most weighted injury) $\left.{ }^{2}\right]$ \\
\hline RTS & $\begin{array}{l}\text { Respiratory rate, systolic blood pressure, Glasgow Coma } \\
\text { Scale }\end{array}$ & $\begin{array}{l}\text { Sum of [(RR value) ' } 0.2908 ; \text { (SBP value) '0.7326; (GCS } \\
\text { value) '0.9368] }\end{array}$ \\
\hline TRISS & RTS, ISS, age, mechanism of injury (blunt or penetrating) & $\begin{array}{l}b=-2.5355+\text { RTS }^{\prime} 0.9934+\text { ISS }^{\prime}-0.0651+(\text { age.points }) \\
-1.1360 \text { Predicted death rate }=1 /\left(1+e^{b}\right)\end{array}$ \\
\hline
\end{tabular}

The Abbreviated Injury Scale (AIS) defines the severity of trauma for each organ system, and injuries are classified in six groups (minor: 1; moderate: 2, serious: 3, severe: 4, critical: 5, and maximal: 6 points). The corresponding points are used for the calculation of Injury Severity Score (ISS) and New Injury Severity Score (NISS). For ISS, the body is divided into six zones (head and neck; face; chest; abdomen and pelvic contents; extremity and pelvic girdle; external injuries). A value between 0 and 4 is defined for specific ranges of respiratory rate (RR), systolic blood pressure (SBP), and Glasgow Coma Scale (GCS) to calculate the Revised Trauma Score (RTS). Coefficients are used to calculate RTS and Trauma and Injury Severity Score (TRISS). Coefficients defined for penetrating injuries are used in calculation of TRISS in our study 


\section{RESULTS}

\section{Baseline Characteristics}

Seventy-seven consecutive patients underwent surgical repair due to penetrating cardiovascular trauma during the study period. About 19\% $(n=15)$ of all the patients were female. The mean age of the patients was $28.7 \pm 10.7$ years (range: 15 to 60 years). There was no significant difference between the ages of the survivors and nonsurvivors
(28.6 \pm 11.3 vs. $27.6 \pm 10.6$, respectively; $P=0.72$ ). Three patients had schizophrenia, one patient had arterial hypertension, and no other chronic diseases were present. Injured structures and related mortality are shown in Table 2. About 17\% $(n=13)$ of the patients had multiple cardiovascular injuries. About $53 \%(n=41)$ of the patients had accompanying organ injuries (17 lung injuries, 12 intra-abdominal organ injuries, eight bone fractures, four liver injuries, and four peripheral nerve damages). About 27\% ( $n=21)$ of the 77 patients died (two

Table 2. Patients' injured structures and related mortality.

\begin{tabular}{|c|c|c|c|}
\hline & Number of cases & $\begin{array}{l}\text { Number of additional non- } \\
\text { CV injuries }\end{array}$ & Mortality (n) \\
\hline Heart* $^{*}$ & 13 & 4 & 7 \\
\hline Thoracic aorta** & 2 & 2 & 2 \\
\hline Innominate vein & 1 & 1 & 1 \\
\hline Carotid & 1 & - & 1 \\
\hline Pulmonar vessels & 2 & 2 & 2 \\
\hline Abdominal aorta*** & 3 & 3 & 3 \\
\hline Vena cava inferior & 5 & 5 & 3 \\
\hline Iliac artery*** & 2 & 2 & 1 \\
\hline Femoral vein & 3 & - & 1 \\
\hline Femoral artery $^{\dagger}$ & 4 & - & - \\
\hline Popliteal artery ${ }^{\dagger+}$ & 4 & 2 & - \\
\hline Popliteal vein & 1 & - & - \\
\hline Tibial artery & 4 & 4 & - \\
\hline Subclavian vein & 2 & 2 & - \\
\hline Axillary artery ${ }^{+\dagger+}$ & 2 & 1 & - \\
\hline Axillary vein & 1 & 1 & - \\
\hline Brachial artery $^{\ddagger}$ & 9 & 1 & - \\
\hline Radial artery & 6 & 4 & - \\
\hline Ulnar artery ${ }^{\neq \neq}$ & 3 & 3 & - \\
\hline Cephalic/basilic vein & 2 & - & - \\
\hline External jugular vein & 2 & - & - \\
\hline Occipital artery & 1 & 1 & - \\
\hline Internal thoracic artery ${ }^{\ddagger \neq \neq}$ & 2 & 1 & - \\
\hline Intercostal artery & 2 & 2 & - \\
\hline
\end{tabular}

Concomitant injuries of cases with multiple cardiovascular (CV) injuries are marked with symbols. The number of patients with accompanying nonvascular injuries (lung, bowel, liver, bone, or nerves) is enlisted. Mortality among injuries is given as numbers. ${ }^{*}$ one case with left anterior descending artery injury; ${ }^{* *}$ one case with pulmonary hilar vessel injury; ${ }^{* * *}$ one case with ipsilateral iliac vein injury; ${ }^{\dagger}$ three cases with ipsilateral femoral vein injury; ${ }^{{ }^{\dagger}+}$ two cases with ipsilateral popliteal vein injury; ${ }^{+{ }^{+\dagger}}$ two cases with

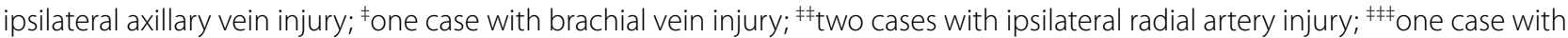
pericardial penetration 
patients with stab wounds and 19 patients with shotgun wounds). About $47 \%(n=36)$ of the study population had a shotgun wound, $41 \%(n=32)$ had a stab wound, and $12 \%$ $(n=9)$ had injuries caused by other sharp materials. None of the six patients with cardiac injuries due to shotgun wounds survived. The patients with shotgun wounds had a higher mortality rate than those with stab wounds $(P<0.001)$. The hemodynamic statuses at admission of the survivors and nonsurvivors are given in Table 3. About $61 \%(n=13)$ of the nonsurvivors were on cardiopulmonary resuscitation on admission. Six patients with thoracic trauma underwent resuscitative emergency department thoracotomy (EDT). Three of six patients could survive the operation, but only one case could be discharged from the hospital (16\% survival). About $51 \%(n=39)$ of the patients had ISS > 15; a mortality rate of 26\% ( $n=20)$ was present among this group. Saphenous vein graft ( $n=28 ; 17$ patients), prosthetic graft interpositions $(n=3)$, and venous patch repair $(n=2)$ were used. The remaining patients were treated with end-to-end anastomosis or primary repair. Five patients needed fasciotomy after vascular repair; no amputations were required. Teflon-pledgeted mattress sutures $(n=12)$ and a pericardial patch $(n=1)$ were used for cardiac injuries. One patient required coronary artery bypass graft procedure at an external center due to the distal left anterior descending artery injury following suture repair of cardiac injury at the study hospital.

\section{Validation of Risk Scores}

Mean ISS, NISS, TRISS, and RTS of all the patients, survivors and nonsurvivors, are shown in Table 4. The risk scores were compared with the rate of survival. ISS, NISS, TRISS, and RTS were correlated with mortality in our study population (Mann-Whitney $U$ test, $P<0.001$ for each). When ISS, NISS, and TRISS values increase and the RTS values decreased, the mortality rate increased. ROC analysis was performed

Table 3. Outcomes of patients according to the measured blood pressures on arrival at the hospital.

\begin{tabular}{l|c|c|c|c}
\hline \multirow{2}{*}{$\begin{array}{c}\text { Systolic blood pressure } \\
(\mathbf{m m H g})\end{array}$} & Injury location & Patient $(\mathbf{n})$ & Survivor (n) & Nonsurvivor (n) \\
\hline \multirow{2}{*}{ Immeasurable } & Cardiac & 4 & - & 4 \\
\hline \multirow{2}{*}{$\leq 60$} & Vascular & $12^{*}$ & 3 & 9 \\
\cline { 2 - 5 } & Cardiac & 2 & - & 1 \\
\cline { 2 - 5 } $60-90$ & Vascular & $2^{* *}$ & 4 & 2 \\
\hline \multirow{2}{*}{$\geq 90$} & Cardiac & 6 & 15 & 2 \\
\cline { 2 - 5 } & Vascular & $17^{\dagger}$ & 1 & - \\
\hline
\end{tabular}

Of all patients, $21 \%(n=16)$ had immeasurable blood pressure and required cardiopulmonary resuscitation during transport or following arrival to the hospital, all of them had signs of life at the trauma scene; $5 \%(n=4)$ had profound hypotension ( $\leq 60$ $\mathrm{mmHg}$ systolic arterial pressure [SAP]) at admission; $30 \%(n=23)$ were hypotensive $(60-90 \mathrm{mmHg}$ SAP); and only $44 \%(n=34)$ were hemodynamically stable ( $\geq 90 \mathrm{mmHg}$ SAP)

*seven truncal, five junction vessel injuries; ${ }^{* *}$ two truncal vascular injuries; ${ }^{\dagger}$ five junctional, eight truncal, four extremity vascular injuries; ${ }^{\dagger+}$ five truncal, five junctional, 23 extremity vascular injuries

Table 4. Mean scores of all cardiovascular trauma patients, survivors, and nonsurvivors.

\begin{tabular}{l|c|c|c|c}
\hline Parameters & $\begin{array}{c}\text { All patients } \\
\text { (mean } \pm \text { SD) }\end{array}$ & Survivor (mean \pm SD) & $\begin{array}{c}\text { Nonsurvivor } \\
(\text { mean } \pm \text { SD) }\end{array}$ & $P$-value \\
\hline ISS & $13.5 \pm 8.1$ & $10.2 \pm 5.7$ & $22.1 \pm 7.38$ & $<0.001$ \\
\hline NISS & $19.9 \pm 12.7$ & $14.7 \pm 8.99$ & $33.6 \pm 10.9$ & $<0.001$ \\
\hline TRISS & $24.7 \pm 39.9$ & $6.9 \pm 21.7$ & $72.3 \pm 38.8$ & $<0.001$ \\
\hline RTS & $5.7 \pm 3.0$ & $7.09 \pm 1.8$ & $2.15 \pm 2.7$ & $<0.001$ \\
\hline
\end{tabular}

The significance of scores for prediction of mortality is analyzed using Mann-Whitney $\mathrm{U}$ test ISS=Injury Severity Score; NISS=New Injury Severity Score; RTS=Revised Trauma Score; SD=standard deviation; TRISS=Trauma and Injury Severity Score 
to assess the correlation between the calculated risks and mortality. The calculated cut-off values and area under the curve (AUC) in ROC analysis was 14.5 (AUC=0.890) for ISS, 19 (AUC=0.896) for NISS, and 7.6 (AUC=0.943) for TRISS $(P<0.001$ for each). ROC curves of the three scoring systems are presented in Figure 1. The ideal cut-off value for RTS was 6.27 (AUC=0.915), and the reverse relation of the augmented score and diminished mortality is shown on a second ROC curve (Figure 2). Additionally, by performing a univariate logistic regression analysis, ISS (odds ratio [OR]: 0.261, 95\% confidence interval [CI]: $1.125-1.498, P<0.001)$, NISS (OR: $0.180,95 \%$ Cl: $1.094-1.309, P<0.001$ ), TRISS (OR: $0.004,95 \%$ Cl: $1.002-1.005, P<0.001)$, and RTS (OR: $-0,001,95 \%$ Cl: $0.999-$ $1.000, P<0.001)$ were significantly associated with mortality in all the penetrating cardiovascular injuries.

The mean risk scores of patients with and without cardiac injuries are shown separately in Table 5 . The mortality rate of patients with penetrating cardiac injury was 53\% $(n=7 / 13)$. TRISS and RTS results correlated with mortality for cardiac injuries (Mann-Whitney $U$ test, $P=0.003$ and $P=0.01$, respectively). ISS and NISS results were not correlated with

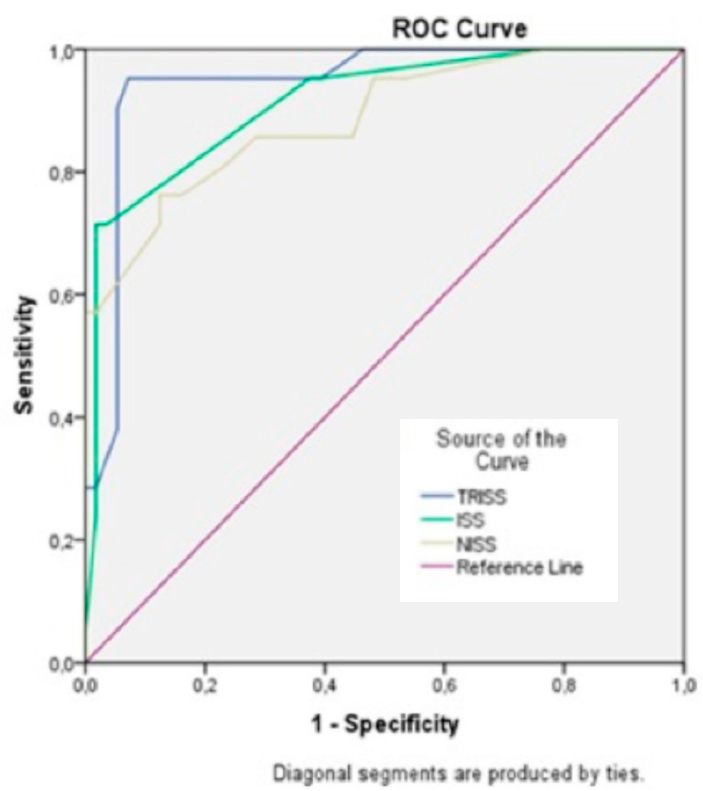

\begin{tabular}{lcccccc} 
& Cut-off & Sensitivity & Specificity & PPV & NPV & $P$-value \\
\hline ISS & 14.5 & 95.2 & 62.5 & 48.8 & 97.2 & $<0.001$ \\
NISS & 19 & 85.7 & 74.0 & 52.9 & 93.0 & $<0.001$ \\
TRISS & 7.6 & 95.2 & 92.2 & 83.3 & 98.1 & $<0.001$
\end{tabular}

Fig. 1 - Receiver operating characteristic (ROC) analysis of ISS, NISS, and TRISS for the risk of mortality in cardiovascular injuries. Cut-off values of risk scores in the prediction of mortality. ISS=Injury Severity Score; NISS=New Injury Severity Score; $N P V=$ negative predictive value; $P P V=$ positive predictive value; TRISS=Trauma and Injury Severity Score. mortality for cardiac injuries (Mann-Whitney $U$ test, $P>0.05$ ) (Table 5). The cut-off values in cardiac injuries and in ROC analysis was 20.5 (AUC $=0.786, P>0.05$, sensitivity: 57\%, specificity: 100\%) for ISS, 22.5 ( $A \cup C=0.738, P>0.05$, sensitivity: 85\%, specificity: $50 \%$ ) for NISS, 12.6 (AUC $=0.929, P<0.05$, sensitivity: $85 \%$, specificity: $100 \%$ ) for TRISS, and 5.61 (AUC $=0.929, P<0.05$, sensitivity: $85 \%$, specificity: 100\%) for RTS.

Among 64 patients with vascular injury, mortality rate was $22 \%(n=14)$. ISS, NISS, TRISS, and RTS have shown a strong correlation with mortality in patients with vascular injuries (Mann-Whitney $U$ test, $P<0.001$ for each) (Table 5). The calculated cut-off values and AUC in vascular injuries and in ROC analysis was 14.5 (AUC $=0.896, P<0.001$, sensitivity: $92 \%$, specificity: $76 \%$ ) for ISS, 17.5 (AUC $=0.893, P<0.001$, sensitivity: 78\%, specificity: 64\%) for NISS, 24.5 (AUC $=0.946, P<0.001$, sensitivity: $92 \%$, specificity: $88 \%$ ) for TRISS, and 6.74 (AUC $=0.929$, $P<0.001$, sensitivity: $85 \%$, specificity: $100 \%$ ) for RTS.

\section{DISCUSSION}

Civilian cardiovascular trauma has always been a challenge for physicians, and it has been evaluated since the birth of cardiovascular surgery ${ }^{[19]}$. Victims of penetrating cardiovascular injuries mostly die on the scene or during

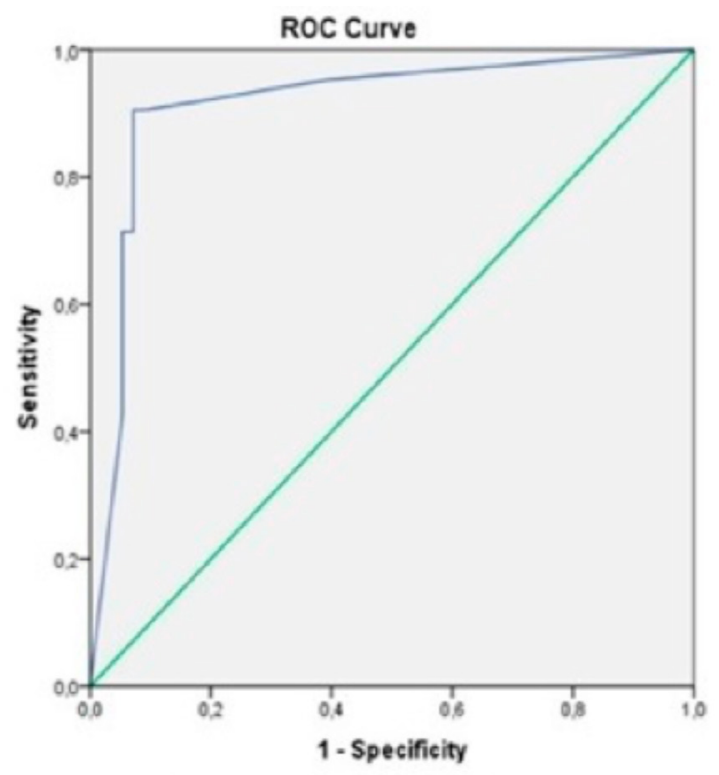

Diagonal segments are produced by ties

\begin{tabular}{lcccccc} 
& Cut-off & Sensitivity & Specificity & PPV & NPV & $P$-value \\
\hline RTS & 6.27 & 90.5 & 92.9 & 82.9 & 96.3 & $<0,001$
\end{tabular}

Fig. 2 - Receiver operating characteristic (ROC) analysis of RTS for the risk of mortality in cardiovascular injuries. Cut-off values of risk scores in the prediction of mortality. NPV=negative predictive value; $P P V=$ positive predictive value; $R T S=$ Revised Trauma Score. 
transfer to a trauma facility. Overall survival has been reported between $11 \%$ and $73 \%$ for patients with cardiac injuries who arrive at a trauma center with signs of life ${ }^{[20,21]}$. Although overall mortality rates of 1.3\%-10\% for vascular trauma have been published in reports from high-level urban trauma centers, $13 \%-20 \%$ mortality rate range is reported in rural centers for vascular injuries, which is consistent with our results ${ }^{[22,23]}$. Our relatively high mortality rate ( $27 \%$ among all cases) is due to the high frequency of shotgun injuries and surgical management, including EDT, even if the patients had no vital signs and were resuscitated on arrival at the hospital. In our study, a 16\% survival rate was found in EDT, similar to previously published survival rates ${ }^{[24]}$. The improvement of the ambulance system results in the arrival of more severely wounded patients at our hospital. Therefore, the overall inhospital mortality rate may increase. Of note, the support of a heart-lung machine was not available in the hospital during this study period. Although its use is reported to be occasional in trauma, it could improve the efficiency of the cardiovascular surgeon, especially in major cardiac injuries ${ }^{[25]}$.

To determine the efficacity of the allocated resources, as well as the training of health-care providers, the patient and treatment profile should be understood. With the use of an appropriate scoring system, the severity of trauma can be assessed, and a prediction of outcomes can be made on arrival at the hospital. In mixed trauma populations, the most commonly accepted threshold of ISS is 15, and it also indicates major trauma with substantially increased mortality, although higher cut-off values for mortality have been reported ${ }^{[26,27]}$. According to the analysis of nearly nine million trauma victims, $93 \%$ of urban and rural patients had ISS $<9$, and less than $1 \%$ of the patients had ISS $>15^{[28]}$. The proportion of our patients with ISS > 15 (51\%) was relatively high. This high proportion shows the more severe injuries to be dealt with when the cardiovascular system is involved. However, the mortality rate of a population with heterogeneous organ traumas and the results of trauma with the involvement of a special organ system might have different thresholds ${ }^{[26,29,30]}$.

When grouped as cardiovascular trauma, all of the studied scores were correlated with mortality using a Mann-Whitney $U$ test $(P<0.001$ for each) and could be put in order as TRISS (AUC $=0.943)$, RTS (AUC=0.915), NISS (AUC=0.896), and ISS ( $A \cup C=0.890$ ) by decreasing force with regard to their AUCS (Table 4, Figures 1 and 2).

Subgroup analysis revealed that NISS had no correlation with mortality, while ISS had a lower significance $(P=0.035)$ than TRISS $(P=0.002)$ and RTS $(P=0.008)$ by considering penetrating cardiac injuries (Table 5). A ROC analysis for cardiac injuries revealed that ISS and NISS had no significant effect on mortality prediction ( $P<0.05$ for both). TRISS and RTS are more accurate regarding sensitivity, specificity, and AUC in ROC analysis involving penetrating cardiac injuries. This means that components of RTS (respiratory rate, besides blood pressure and Glasgow Coma Score) and TRISS (age) have a positive effect on outcome prediction. Hemodynamic status and physiological parameters at the time of admission in cardiac injuries seem to be better predictors of mortality, compared to anatomical region-based risk classifications. Topal et al. ${ }^{[21]}$ previously reported that TRISS was effective in predicting mortality in cardiac injuries in an urban center. The results of our study confirm the validity of TRISS and RTS with the high positive and negative predictive values in patients with penetrating cardiovascular trauma. Minor differences in favor of TRISS in terms of negative and positive predictive values may be related to the numerical expression of the results. RTS values are derived from a shorter range.

Table 5. Mean risk scores of patients with cardiac and vascular injuries.

\begin{tabular}{l|c|c|c|c}
\hline & $\begin{array}{c}\text { All patients } \\
(\mathbf{m e a n} \pm \text { SD) }\end{array}$ & Survivors (mean \pm SD) & $\begin{array}{c}\text { Nonsurvivors } \\
(\mathbf{m e a n} \pm \text { SD) }\end{array}$ & $P$-value \\
\hline Cardiac injury $(\mathrm{n}=13)$ & & & & \\
\hline ISS & $20.38 \pm 7.06$ & $16.000 \pm 0.000$ & $24.143 \pm 8.009$ & 0.035 \\
\hline NISS & $29.07 \pm 9.46$ & $24.67 \pm 8.16$ & $32.86 \pm 9.35$ & 0.132 \\
\hline TRISS & $41.21 \pm 46.36$ & $3.250 \pm 1.475$ & $73.757 \pm 40.260$ & 0.002 \\
\hline RTS & $4.38 \pm 3.31$ & $7.110 \pm 0.462$ & $2.043 \pm 2.820$ & 0.008 \\
\hline Vascular Injury (n=64) & & & & \\
\hline ISS & $12.1 \pm 7.67$ & $9.580 \pm 5.679$ & $21.143 \pm 7.145$ & $<0.001$ \\
\hline NISS & $18.04 \pm 12.53$ & $13.580 \pm 8.401$ & $34.000 \pm 12.006$ & $<0.001$ \\
\hline TRISS & $28.6 \pm 42.7$ & $7.390 \pm 23.022$ & $71.650 \pm 39.597$ & $<0.001$ \\
\hline RTS & $5.7 \pm 3.05$ & $7.089 \pm 1.936$ & $2.216 \pm 2.838$ & $<0.001$ \\
\hline
\end{tabular}

The validation of risk scores for mortality among cardiac $(n=13)$ and vascular injuries $(n=64)$ is made using the Mann-Whitney $U$ test. ISS and NISS did not predict mortality for penetrating cardiac injuries ( $P>0.05$, both)

ISS=Injury Severity Score; NISS=New Injury Severity Score; RTS=Revised Trauma Score; SD=standard deviation; TRISS=Trauma and Injury Severity Score 
For vascular injuries, all risk scores were correlated with mortality using Mann-Whitney $U$ test $(P<0.001$ for each) and ROC analysis $P<0.001$ for each) (Table 5 ).

\section{CONCLUSION}

Penetrating cardiovascular trauma is one of the most significant life-threatening injuries. Geographic disparities, as well as increased firearm usage, may contribute to negative effects in lethal outcomes in rural areas. TRISS has shown the strongest correlation for predicting in-hospital mortality in victims of cardiovascular trauma. ISS and NISS did not correlate with the outcomes of cardiac injuries. TRISS and RTS can be used for assessment of the risk for mortality in victims of penetrating cardiovascular trauma.

\section{No financial support. \\ No conflict of interest.}

\section{Authors' roles \& responsibilities}

AAA Substantial contributions to the conception or design of the work; or the acquisition, analysis, or interpretation of data for the work; final approval of the version to be published

ES

Substantial contributions to the conception or design of the work; or the acquisition, analysis, or interpretation of data for the work; final approval of the version to be published

FAB

Substantial contributions to the conception or design of the work; or the acquisition, analysis, or interpretation of data for the work; final approval of the version to be published

\section{REFERENCES}

1. Türkiye İstatistik Kurumu (2018). Haber Bülteni Ölüm Nedeni İstatistikleri Sayl: 27620 [Internet]. [cited 2019 Mar 12]. Available from: www.tuik.gov. tr/PdfGetir.do?id=27620.

2. Türkiye Istatistik Kurumu (2009-2017). Yaş Grubu ve Cinsiyete Göre Seçilmiş Ölüm Nedenlerinin Dağılımı - Distribution of selected causes of death by age group and gender [Internet]. [cited 2020 Mar 12]. Available from: http:// tuik.gov.tr/PrelstatistikTablo.do?istab_id=2592

3. Butchart A, Mikton C, Dahlberg LL, Krug EG. Global status report on violence prevention 2014. Inj Prev. 2015;21(3):213. doi:10.1136/ injuryprev-2015-041640.

4. Helling TS. Trauma care at rural level III trauma centers in a state trauma system. J Trauma. 2007;62(2):498-503. doi:10.1097/01.ta.0000197671.00818.76.

5. Zakariassen E, Østerås $\varnothing$, Nystøyl DS, Breidablik HJ, Solheim E, Brattebø G, et al. Loss of life years due to unavailable helicopter emergency medical service: a single base study from a rural area of Norway. Scand J Prim Health Care. 2019;37(2):233-41. doi:10.1080/02813432.2019.1608056.
6. Pape J, Swart O, Duvenage R. Four-year review of admissions to a South African regional hospital general surgery department. S Afr Med J. 2019;109(2):122-6. doi:10.7196/SAMJ.2019.v109i2.13433.

7. Oliveira APC, Gabriel M, Poz MRD, Dussault G. Challenges for ensuring availability and accessibility toin health care services under Brazil's unified health System (SUS). Cien Saude Colet. 2017;22(4):1165-80. Erratum in: Cien Saude Colet. 2017;22(7):2397-424. doi:10.1590/1413-81232017224.31382016.

8. Harris JD, Hosford CC, Sticca RP. A comprehensive analysis of surgical procedures in rural surgery practices. Am J Surg. 2010;200(6):820-5; discussion 825-6. doi:10.1016/j.amjsurg.2010.07.029.

9. Sönmez M. [Causes and consequences of emigration in Muş province]. Türk Coğrafya Derg. 2010(55):45-57. Turkish.

10. Rotondo M, Cribari C, Smith R, Trauma ACoSCo. Resources for optimal care of the injured patient. Chicago: American College of Surgeons. 2014; 6p.

11. Greenspan L, McLellan BA, Greig H. Abbreviated injury scale and injury severity score: a scoring chart. J Trauma. 1985;25(1):60-4. doi:10.1097/00005373198501000-00010.

12. Moore EE, Cogbill TH, Malangoni MA, Jurkovich GJ, Shackford SR, Champion HR, et al. Organ injury scaling. Surg Clin North Am. 1995;75(2):293-303. doi:10.1016/s0039-6109(16)46589-8.

13. Palmer CS, Lang J, Russell G, Dallow N, Harvey K, Gabbe B, et al. Mapping abbreviated injury scale data from 1990 to 1998 versions: a stepping-stone in the contemporary evaluation of trauma. Injury. 2013;44(11):1437-42. doi:10.1016/j.injury.2012.08.033.

14. Palmer CS, Franklyn M. Assessment of the effects and limitations of the 1998 to 2008 abbreviated injury scale map using a large population-based dataset. Scand JTrauma Resusc Emerg Med. 2011;19(1):1. doi:10.1186/17577241-19-1.

15. Baker SP, O'Neill B, Haddon W Jr, Long WB. The injury severity score: a method for describing patients with multiple injuries and evaluating emergency care. J Trauma. 1974;14(3):187-96.

16. Osler T, Baker SP, Long W. A modification of the injury severity score that both improves accuracy and simplifies scoring. JTrauma. 1997;43(6):922-5; discussion 925-6. doi:10.1097/00005373-199712000-00009.

17. Champion HR, Sacco WJ, Copes WS, Gann DS, Gennarelli TA, Flanagan ME. A revision of the trauma score. J Trauma. 1989;29(5):623-9. doi:10.1097/00005373-198905000-00017.

18. Boyd CR, Tolson MA, Copes WS. Evaluating trauma care: the TRISS method. Trauma score and the injury severity score. J Trauma. 1987;27(4):370-8.

19. Mattox KL, Feliciano DV, Burch J, Beall AC Jr, Jordan GL Jr, De Bakey ME. Five thousand seven hundred sixty cardiovascular injuries in 4459 patients. Epidemiologic evolution 1958 to 1987. Ann Surg. 1989;209(6):698-705; discussion 706-7. doi:10.1097/00000658-198906000-00007.

20. Morse BC, Mina MJ, Carr JS, Jhunjhunwala R, Dente CJ, Zink JU, et al. Penetrating cardiac injuries: a 36-year perspective at an urban, level I trauma center. J Trauma Acute Care Surg. 2016;81(4):623-31. doi:10.1097/ TA.0000000000001165.

21. Topal AE, Celik Y, Eren MN. Predictors of outcome in penetrating cardiac injuries. J Trauma. 2010;69(3):574-8. doi:10.1097/TA.0b013e3181 bc783a.

22. Humphrey PW, Nichols WK, Silver D. Rural vascular trauma: a twenty-year review. Ann Vasc Surg. 1994;8(2):179-85. doi:10.1007/BF02018867.

23. Oller DW, Rutledge R, Clancy T, Cunningham P, Thomason M, Meredith W, et al. Vascular injuries in a rural state: a review of 978 patients from a state trauma registry. JTrauma. 1992;32(6):740-5; discussion 745-6. doi:10.1097/00005373$199206000-00012$.

24. Kaljusto ML, Skaga NO, Pillgram-Larsen J, Tønnessen T. Survival predictor for penetrating cardiac injury; a 10-year consecutive cohort from a scandinavian trauma center. Scand JTrauma Resusc Emerg Med. 2015;23:41. doi:10.1186/ s13049-015-0125-z.

25. Mollberg NM, Tabachnik D, Farjah F, Lin FJ, Vafa A, Abdelhady K, et al. Utilization of cardiothoracic surgeons for operative penetrating thoracic trauma and its impact on clinical outcomes. Ann Thorac Surg. 2013;96(2):44550. doi:10.1016/j.athoracsur.2013.04.033.

26. Aydin SA, Bulut M, Ozgüç H, Ercan I, Türkmen N, Eren B, et al. Should the new injury severity score replace the injury severity score in the trauma and injury severity score? Ulus Travma Acil Cerrahi Derg. 2008;14(4):308-12. 
27. Palmer CS, Gabbe BJ, Cameron PA. Defining major trauma using the 2008 abbreviated injury scale. Injury. 2016;47(1):109-15. doi:10.1016/j. injury.2015.07.003.

28. Jarman MP, Castillo RC, Carlini AR, Kodadek LM, Haider AH. Rural risk: geographic disparities in trauma mortality. Surgery. 2016;160(6):1551-9.

29. Şengül AT, Kutlu T, Büyükkarabacak YB, Yetim TD, Bekdemir ÖS, Öztürk C, et al. [Effects of trauma scores on prognosis in chest traumas]. Turk Gogus Kalp Dama. 2012;20(4):805-11. doi:10.5606/tgkdc.dergisi.2012.158. Turkish.

30. Sartorius D, Le Manach Y, David JS, Rancurel E, Smail N, Thicoïpé M, et al. Mechanism, glasgow coma scale, age, and arterial pressure (MGAP): a new simple prehospital triage score to predict mortality in trauma patients. Crit Care Med. 2010;38(3):831-7. doi:10.1097/CCM.0b013e3181cc4a67. 